\title{
The Effect of Stray Capacitance to the Common Mode Current on Three-Phase System
}

Muhammad S. Alamsyah, Francinei L. Vieira, Heyno Garbe Institute of Electrical Engineering and Measurement Technology Leibniz University Hannover

Hannover, Germany

alamsyah@geml.uni-hannover.de

\author{
Sebastian Koj \\ EMC and Antenna \\ IAV GmbH \\ Gifhorn, Germany \\ sebastian.koj@ieee.org
}

\begin{abstract}
The common-mode (CM) current phenomena is one of many problems in the EMC world due to the radiated magnetic field caused by it. A power transmission line with a delta-connection both generator and load normally do not have a connection to ground to establish a line for the return current. To determine the $\mathrm{CM}$ current, finding the stray capacitances to the ground is highly important because they are used as the return path for the CM current. In this paper, the investigation of predicting the $\mathrm{CM}$ current flowing through the stray capacitances will be done at a three-phase equivalent system of a wind turbine (WT). The wind turbine body is the place where the CM current flows, due to the stray capacitances between the power cables and the WT body around it. The $\mathrm{CM}$ current can be determined using the current magnitudes in a pointer-image method, which has a good agreement for $\mathrm{CM}$ current prediction and it might become a very useful tool applicable to measurements.
\end{abstract}

Keywords-common mode, EMC, pointer-image, stray capacitance, wind energy.

\section{INTRODUCTION}

Renewable energy power plant installations are rising every year due to incentives aiming the green energy targets for the future [1], one of them is a wind energy conversion system, also known as wind turbine (WT). Like any other electrical and electronic equipment, WT must have their electromagnetic (EM) performance analyzed because the WT acts as an unintentional radiator. This performance must comply with the national and international directives, such as the EU-directive 2014/30/EU [2], in order to avoid disturbance in adjacent systems, in particular, radio communication and terrestrial navigation services of security and first-aid organizations [3]. EM disturbances caused by WT both in the form of conducted and radiated emissions have been discussed briefly in [4].

Due to size dimensions, only in-situ radiated emission measurements are performed on WTs and be compared with the limits in CISPR 11 [12]. Those tests have to consider environmental and WT measurements, i.e., the WT shall be switched off from the grid. Besides that, the measurements must be performed at different positions and may be influenced by weather conditions, creating long-lasting measurement campaigns with large data uncertainty.

An alternative approach to predict the radiated emissions using the measurement of the CM (commonmode) current produced from the power line are presented in [5], which describes a method that correlates the CM current with the frequencies at which the radiated emissions occur, independently of the surrounding noise and weather conditions. The CM current propagation along power line inside the WT at on process and shutdown conditions are explained in [6]. In [3], further development of this technique is analyzed, considering different WT heights when estimating the maximum magnetic field from the $\mathrm{CM}$ current. While the power level did not show influence on the method, the height dependence is an indication that standing waves occur. Different construction WT tower types are considered for maximum and minimum estimation of the magnetic field [7].

The measured CM current provided a piece of useful information on which frequency the radiated magnetic field occurred. However, there are several limitations on measuring CM current directly at the power line of a WT, such as the number of cable bundles in WT and the limited current clamp size.

In this paper, a simplified method of predicting the CM current on the three-phase system between generator and power converter using a pointer image method is investigated [8]. This method is analyzed with simulations of a wind generator's simplified model. In Section II, the pointer-image method is described. In Section III, a threephase WT example is presented as a case study. In the following Section IV, the results are shown and the application of this theory is discussed. Lastly, the conclusions are summarized in Section V.

\section{The PoINTER-IMAge MethoD}

In three-phase power systems, a balanced system will show a perfect triangle pointer current image, as seen in Fig. 1 [9]. Meanwhile for an unbalanced system, for example, a 3-phase 4-wire connection, a current running at the neutral wire is expected, as shown in Fig. 2. Equation (1) correlates the neutral current $\left(I_{N}\right)$ with the phase currents.

$$
I_{1}+I_{2}+I_{3}=I_{N}
$$

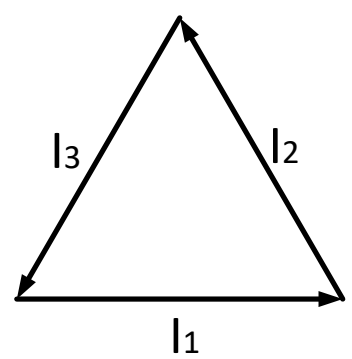

Fig. 1. Three-phase system pointer current image for both balanced $\Delta$ and Y-system 


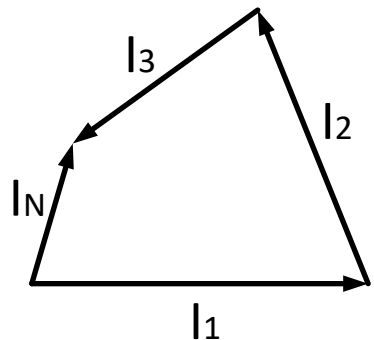

I1

Fig. 2. Three-phase system pointer current image for both unbalanced $\Delta$ - and Y-system

The neutral current could also be assumed as the CM current in this case due to the usage of the neutral wire as a return path of the unbalanced current. In the case of a wind turbine, the power line inside it uses a delta connection which does not have a neutral wire that could be used to determine the CM current, then the challenge arises. In this paper, the pointer image method will be used to obtain the $\mathrm{CM}$ current. It could be done by measuring the current flowing at each phase $\left(\mathrm{P}_{1}, \mathrm{P}_{2}\right.$, and $\left.\mathrm{P}_{3}\right)$ and each two-phase bundle $\left(\mathrm{P}_{1} \& \mathrm{P}_{2}, \mathrm{P}_{2} \& \mathrm{P}_{3}\right.$ and $\left.\mathrm{P}_{3} \& \mathrm{P}_{1}\right)$. For power lines with $n$ bundles, $2 n-1$ measurements are necessary to determine the $I_{C M}$.

\section{CASE STUdy}

The equivalent circuit of the wind turbine power line modelling is done in LTspice [10] with a simplified circuit to show the behavior of the CM current due to the stray capacitances. The circuit consists of the voltage source connected directly to the load using a $1 \mathrm{~m}$ cable. The cable arrangement is assumed to be located near the WT wall so that compared to the cable size, the WT wall will be assumed flat, as displayed in Fig. 3.

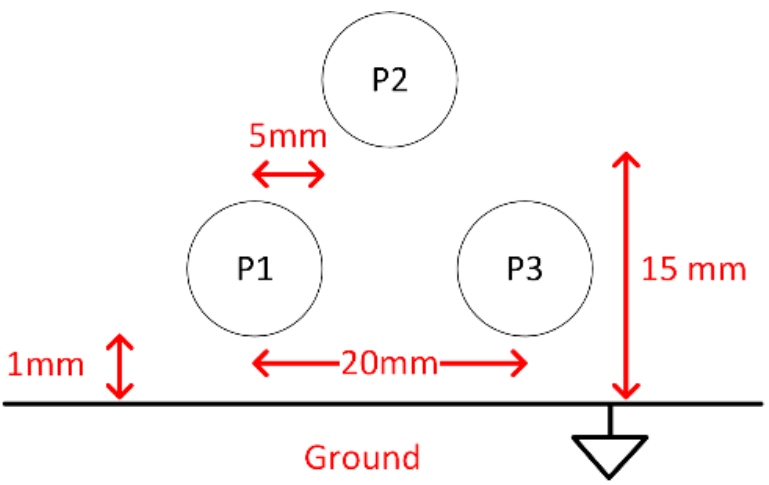

Fig. 3. Power cable arrangement

The capacitances between each phase-to-phase and each phase-to-ground are obtained as in (2) and (3) [11] and the resulting values are shown in Table 1.

Phase-to phase capacitance:

$$
C=\frac{\pi \varepsilon_{0} l}{\ln \left(\frac{d}{r}\right)}
$$

Where $C$ is the capacitance $(\mathrm{F}), l$ is the cable length $(\mathrm{m})$, $d$ is the distance between adjacent cable from each core (m), and $r$ is the cable radius $(\mathrm{m})$.
Phase-to-ground capacitance:

$$
C=\frac{2 \pi \varepsilon_{0} l}{\ln \left(\frac{2 a}{r}\right)}
$$

Where $C$ is capacitance $(\mathrm{F}), l$ is the cable length $(\mathrm{m}), a$ is the distance between cable core to the ground $(\mathrm{m})$, and $r$ is the cable radius (m).

Table 1. Calculated Capacitance Values

\begin{tabular}{|c|c|}
\hline Capacitance & Value (pF) \\
\hline $\mathrm{C}_{12}$ & 22.48 \\
\hline $\mathrm{C}_{23}$ & 22.48 \\
\hline $\mathrm{C}_{31}$ & 20.03 \\
\hline $\mathrm{C}_{1 \mathrm{G}}$ & 63.44 \\
\hline $\mathrm{C}_{2 \mathrm{G}}$ & 30.99 \\
\hline $\mathrm{C}_{3 \mathrm{G}}$ & 63.44 \\
\hline
\end{tabular}

The modelling will be split into two models:

\section{A. Circuit 1}

This model consists of both source and load as a starconnected source and load with a neutral wire connecting the two midpoints. The source will be sinusoidal $230 \mathrm{~V}$ with $50 \mathrm{~Hz}$ frequency and 120 degrees phase difference between each phase. The load for each phase varies as shown in Table 2 to cause a current flowing in the neutral wire. The schematic is as shown in Fig. 4

\section{TABLE 2. LOAD VARIATION}

\begin{tabular}{|c|c|}
\hline Load & Value $(\mathbf{\Omega})$ \\
\hline $\mathrm{R}_{1}$ & 383.33 \\
\hline $\mathrm{R}_{2}$ & 460 \\
\hline $\mathrm{R}_{3}$ & 766.67 \\
\hline
\end{tabular}

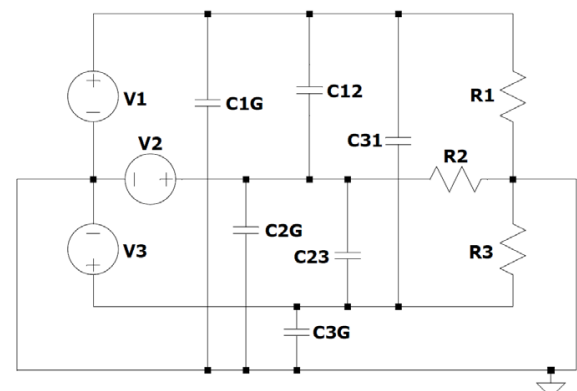

Fig. 4. Circuit 1: Star-connected source and load

\section{B. Circuit 2}

This model consists of a star-connected source and a delta-connected load, as in Fig. 5. A fourth wire is connected to the source as the model of wind turbine body and used as the return path of the common-mode current, connected to each phase by the stray capacitances. The source will be rectangular-shaped, amplitude of $230 \mathrm{~V}$ with $10 \mathrm{kHz}$ frequency and 120 degrees phase difference between each phase. The rectangular-shaped voltage emulates the voltage of a frequency converter, which is usually implemented in modern WTs. The high-frequency source is also used to 
show the behavior of CM current under several frequency bands. The load is $460 \Omega$ for each phase.

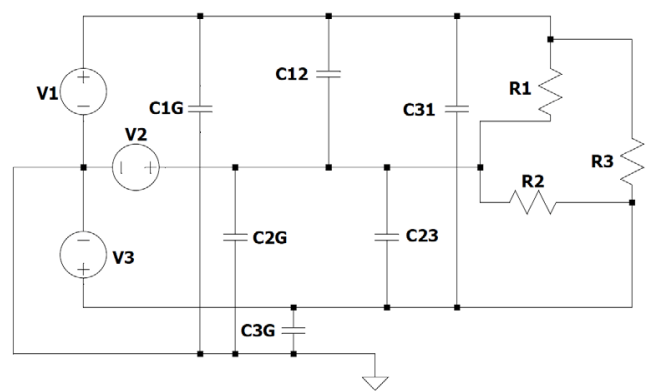

Fig. 5. Circuit 2: Star connected source and delta-connected load

\section{RESULTS AND DISCUSSION}

In this topic, the measured current from each phase $\left(\mathrm{P}_{1}\right.$, $\mathrm{P}_{2}$, and $\left.\mathrm{P}_{3}\right)$ and two-phase bundle $\left(\mathrm{P}_{1} \& \mathrm{P}_{2}\right.$ and $\left.\mathrm{P}_{2} \& \mathrm{P}_{3}\right)$ will be plotted using the pointer-image theory explained in chapter II. The predicted CM current results from pointerimage theory will be compared with the results from LTspice.

\section{A. Circuit 1}

The line current for each phase and the neutral current are obtained from the simulations on LTspice and are shown in the Table 3 . Those currents are plotted digitally to get a quite precise line positioning as displayed in Fig. 6.

TABLE 3. CirCuit 1 CURRENT MEASURED IN
\begin{tabular}{|c|c|}
\hline Current & Value (mA) \\
\hline $\mathrm{P}_{1}$ & 598.117 \\
\hline $\mathrm{P}_{2}$ & 497.589 \\
\hline $\mathrm{P}_{3}$ & 299.273 \\
\hline Neutral & 262.886 \\
\hline $\mathrm{P}_{12}$ & 555.054 \\
\hline $\mathrm{P}_{23}$ & 431.126 \\
\hline
\end{tabular}

The pointer-image is obtained by using $\mathrm{I}_{1}$ magnitude as the reference and then by superimposing $I_{2}$ and $I_{12}$ geometrically, the orientation of $\mathrm{I}_{2}$ is obtained. Using the same procedure for $I_{3}$ and $I_{23}$, the orientation of $I_{3}$ is also obtained [8]. Due to the unbalanced load mentioned in Table 2 , the triangle has a gap which is considered the vectorial representation of $\mathrm{I}_{\mathrm{N}}$ or the $\mathrm{I}_{\mathrm{CM}}$. Then, the length of the $\mathrm{I}_{\mathrm{CM}}$ line along with the comparison with the LTspice $\mathrm{I}_{\mathrm{CM}}$ results are shown in Table 4.

TABLE 4. $\mathrm{I}_{\mathrm{CM}}$ COMPARISON FOR CIRCUIT 1

\begin{tabular}{|c|c|}
\hline $\mathbf{I}_{\mathbf{C M}}$ & Value (mA) \\
\hline LTspice & 262.886 \\
\hline Pointer-Image & 264.602 \\
\hline Error (\%) & 0.65 \\
\hline
\end{tabular}

The error of the pointer-image method is $0.65 \%$, so this method is reliable to be used for predicting the $\mathrm{CM}$ current. For further investigation, the method will be used to predict the CM current for several frequency bands in the next subsection.

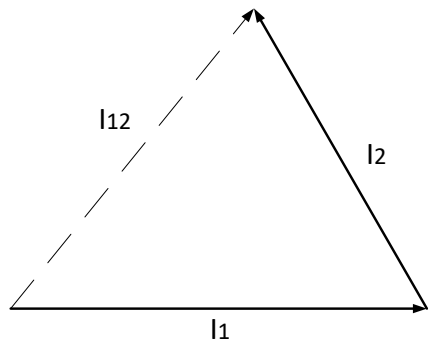

(a)

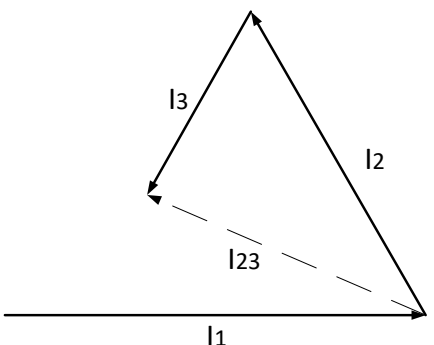

(b)

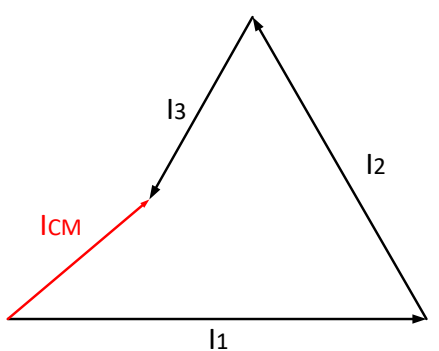

(c)

Fig. 6. Pointer Image for Circuit 1 , (a) $\mathrm{I}_{2} \& \mathrm{I}_{12}$, (b) $\mathrm{I} 3 \& \mathrm{I}_{23}$, and (c) $\mathrm{I}_{\mathrm{CM}}$ vector orientations

\section{B. Circuit 2}

By using the high-frequency rectangular wave, a $\mathrm{CM}$ current on several frequency bands is expected, as it can be observed in Fig. 7. Random points at $10 \mathrm{kHz}, 110 \mathrm{kHz}$ and $1.01 \mathrm{MHz}$ are selected for observation.

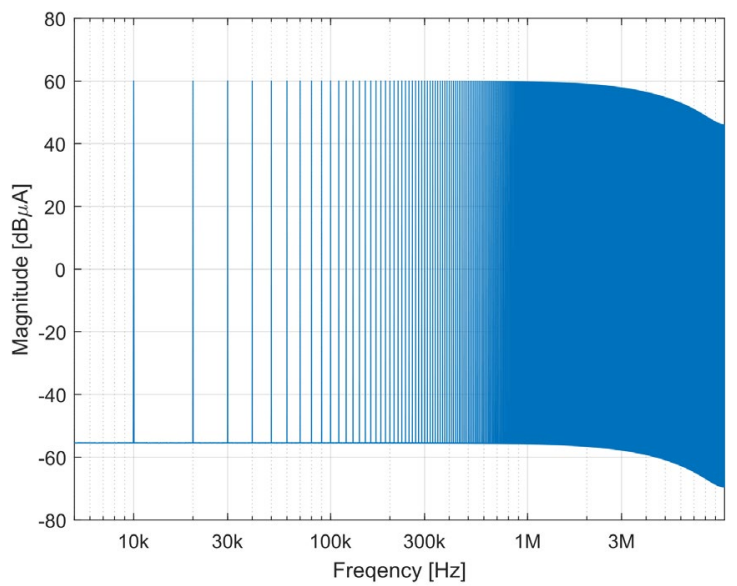

Fig. 5. Circuit 2: Star connected source and delta-connected load

The currents at those three different frequencies for each phase and the neutral current are summarized in the Table 5. 
TABle 5. Circuit 2 CuRRENT MEASURED In LTSPiCE

\begin{tabular}{|c|c|c|c|}
\hline \multirow{2}{*}{ Current } & $\mathbf{1 0} \mathbf{~ k H z}$ & $\mathbf{1 1 0} \mathbf{~ k H z}$ & $\mathbf{1 . 0 1} \mathbf{~ M H z}$ \\
\cline { 2 - 4 } & \multicolumn{3}{|c|}{ Value (mA) } \\
\hline $\mathrm{P}_{1}$ & 1350 & 123.559 & 13.762 \\
\hline $\mathrm{P}_{2}$ & 1350 & 123.17 & 13.679 \\
\hline $\mathrm{P}_{3}$ & 1352 & 121.48 & 11.777 \\
\hline Neutral & 1008 & 1.008 & 0.975 \\
\hline $\mathrm{P}_{12}$ & 1353 & 120.613 & 10.985 \\
\hline $\mathrm{P}_{23}$ & 1349 & 124.434 & 14.624 \\
\hline $\mathrm{P}_{13}$ & 1350 & 123.146 & 13.477 \\
\hline
\end{tabular}

Using the same pointer-image method procedure at subsection $\mathrm{A}$, the $\mathrm{I}_{\mathrm{CM}}$ is obtained as follows in Table 6 .

TABLE 6. I $\mathrm{I}_{\mathrm{CM}}$ COMPARISON FOR CIRCUIT 2

\begin{tabular}{|c|c|c|c|}
\hline \multirow{2}{*}{$\mathbf{I}_{\mathrm{CM}}$} & $\mathbf{1 0} \mathbf{~ k H z}$ & $\mathbf{1 1 0} \mathbf{~ k H z}$ & $\mathbf{1 . 0 1} \mathbf{~ M H z}$ \\
\cline { 2 - 4 } & \multicolumn{3}{|c|}{ Value (mA) } \\
\hline LTSPICE & 1.008 & 1.008 & 0.975 \\
\hline Pointer-Image & 1.06 & 1.014 & 0.974 \\
\hline Error (\%) & 5.16 & 0.60 & 0.10 \\
\hline
\end{tabular}

The error from drawing the pointer-image on the graphic analysis comes from the not fully precise line end drawing of the geometrical meeting point between $\mathrm{I}_{2} \& \mathrm{I}_{12}$ and between $\mathrm{I}_{3} \& \mathrm{I}_{23}$. But overall results are good with $5.16 \%$ as the highest error percentage.

\section{CONCLUSIONS}

The close relation between the radiated magnetic field emission with the CM current the wind turbine has been the biggest motivation for this contribution. Using stray capacitance between the power cable to its wall, the return path for the CM current is expected. A simple circuit simulation to model the test case is presented aiming to obtain the CM current. To overcome the direct measurement limitations, such as the number of cable bundles in WT and the limited current clamp size, the proposed pointer-image method is used to predict the CM current flowing at the WT wall without needing to measure the whole power cable bundles at the same time. This approach is useful to be used for predicting CM current in a three-phase power system, not only in power installations but also transportation system and any other field using a multi-phase power line. The proposed method allows to reduce the time spent on in-situ measurement campaigns as well as the uncertainty caused by the surrounding noise .

\section{REFERENCES}

[1] T. Klaus, C. Vollmer, K. Werner, H. Lehmann, and K. Müschen, "Energy target 2050: 100\% renewable electricity supply," Umwelt Bundesamt, vol. 36, no. 2, pp. 1677-1684, 2017.

[2] Directive 2014/30/EU of THE EUROPEAN PARLIAMENT AND OF THE COUNCIL of 26 February 2014 on the harmonization of the laws of the Member States relating to electromagnetic compatibility.

[3] S. Koj, C. Reschka, S. Fisahn, and H. Garbe, "Radiated electromagnetic emissions from wind energy conversion systems," in IEEE Int. Symp. Electromagn. Compat., pp. 243-248, 2017, doi: 10.1109/ISEMC.2017.8077874

[4] CIGRE WG C4.30, "EMC in Wind Energy Systems." Tech. Rep. CIGRE, 2017.

[5] S. Koj, S. Fisahn, and H. Garbe, "Determination of radiated emissions from wind energy conversion systems," in 2016 Int. Symp. Electromagn. Compat.- EMC EUROPE, 2016, vol. 2016-Novem, pp. 188-192, doi: 10.1109/EMCEurope.2016.7739262.

[6] S. Fisahn, S. Koj, and H. Garbe, "Modelling of multi-megawatt wind turbines for EMI and EMS investigations by a topological approach," in XXXIInd General Assembly and Scientific Symposium of the International Union of Radio Science (URSI GASS), Aug. 2017, p. 4, doi: 10.23919/URSIGASS.2017.8105015.

[7] S. Koj, S. Fisahn, and H. Garbe, "Simplified Procedure to Predict the em Emissions of Wind Energy Conversion Systems," 2018 IEEE Symp. Electromagn. Compat. Signal Integr. Power Integrity, EMC, SI\&PI 2018, no. 1, pp. 423-426, 2018, doi: 10.1109/EMCSI.2018.8495243.

[8] S. Koj, "Messunsicherheit bei in situ Tests der elektromagnetischen Verträglichkeit von Windkraftanlage." Ph.D Thesis Institut für Grundlagen der Elektrotechnik und Messtechnik, Leibniz

[9] H. Haase, H. Garbe, and H. Gerth, Grundlagen der Elektrotechnik, 4th ed. Germany: Schöneworthverlag, 2018, ch. 12, pp. 293-309.

[10] Analog Devices Inc., "LTspice." Wilmington, MA, USA, 2020, [Online]. Available at: http://www.analog.com/LTspice.

[11] E. Hering, R. Martin, M. Stohrer, and H. Käß, "Elektrizität und Magnetismus," in Physik für Ingenieure, Berlin, Heidelberg: Springer Berlin Heidelberg, 2016, pp. 237-375.

[12] IEC/CISPR 11:2015 Industrial, scientific, and medical equipmentRadiofrequency disturbance characteristics - Limits and methods of measurement,Comité international spécial des perturbations radioélectriques Std., 2015. 